\title{
Obesity in Disabled Children and Adolescents
}

\author{
An Overlooked Group of Patients
}

Thomas Reinehr, Michael Dobe, Katrin Winkel, Anke Schaefer, Dieter Hoffmann

\section{SUMMARY}

Background: There is an ongoing debate concerning the relationship between disability and obesity in childhood and adolescence.

Methods: The literature available in Medline was selectively searched for the terms: "(children /OR/ adolescents) /AND/ disability /AND/ (overweight /OR/ obesity)". This search was complemented by inspection of journals in the fields of obesity, pediatrics, and neurology.

Results: A total of 38 relevant articles were identified. All studies agreed that the prevalence of overweight and obesity in children with disabilities was almost twice that in their non-disabled peers. No effective, long-lasting interventions for obesity in disabled children and adolescents have been published.

Conclusion: Since a high proportion of disabled children and adolescents are overweight or obese, effective strategies for preventing and managing excess weight need to be developed so as not to further endanger their social participation. Moreover, risk factors for overweight in disabled children and adolescents should be identified and their weight status carefully monitored.
Gite this as: Dtsch Arztebl Int 2010; 107(15): 268-75 DOl: 10.3238/arztebl.2010.0268

Institut für Pädiatrische Ernährungsmedizin, Vestische Kinder- und Jugendklinik Datteln, Universität Witten/Herdecke: Prof. Dr. med. Reinehr, Dipl.-Psych. Dobe, Dipl.-Psych. Winkel, Dipl.-oec.-troph. Schaefer, Dr. med. Hoffmann

\begin{abstract}
hildren and adolescents with neuromuscular and neurological disorders often have eating disorders in the sense of underweight and malnutrition, especially if these are associated with problems in chewing and swallowing (e1-e3). This article aims to find out whether children and adolescents with disabilities are also often overweight (1). The authors conducted a literature search using the search terms "(children /OR/ adolescents) /AND/ disability /AND/ (overweight /OR/ obesity)". The literature search aimed to describe overweight in children and explain the available therapeutic options. Of 140 hits in the search, 24 articles dealt with the subject matter under investigation (14 review articles, 6 prevalence studies, 3 articles on the sequelae of obesity in patients with disabilities, and 1 article on treatment). The literature search was complemented by selected literature from specialty journals in the fields of pediatrics, neurology, and obesity (1 review article, 5 prevalence studies, 4 on the sequelae of obesity in people with disabilities, 4 on therapeutic approaches).
\end{abstract}

\section{Definitions}

According to Germany's Social Code, Book IX (Neuntes Sozialgesetzbuch, SGB IX), people are disabled if their physical functioning, mental abilities, or psychological health are highly likely not to meet the age appropriate standard for longer than 6 months, thus impairing their participation in social life. International consensus defines overweight in childhood on the basis of population based percentiles for age and sex as a body mass index $(\mathrm{BMI})>90^{\text {th }}$ percentile and obesity as a $\mathrm{BMI}>97^{\text {th }}$ percentile $(\mathrm{e} 4)$.

\section{Children and adolescents with disabilities are often overweight and obese}

Many studies from different countries and populations have consistently shown that children and adolescents with disabilities as well as chronically ill children and adolescents are more commonly overweight and obese than children and adolescents without disabilities (Table 1).

Differences in the prevalence of overweight between children with and without developmental delays are 
Prevalences of overweight and obesity in disabled children and adolescents

\begin{tabular}{|c|c|c|c|}
\hline \multicolumn{4}{|c|}{ a) Compared with healthy children and adolescents } \\
\hline Disability & $\begin{array}{l}\text { Percentage of overweight/ } \\
\text { obesity }\end{array}$ & Healthy comparison group & Country \\
\hline Functionally restricted mobility & $30 \%$ overweight & $16 \%$ overweight & USA (11) \\
\hline Developmental delay & $\begin{array}{l}24 \% \text { overweight } \\
15 \% \text { obese }\end{array}$ & $\begin{array}{l}17 \% \text { overweight } \\
6 \% \text { obese }\end{array}$ & Australia (12) \\
\hline Learning disability & $\begin{array}{l}35 \% \text { overweight } \\
21.9 \% \text { obese }\end{array}$ & $\begin{array}{l}31 \% \text { overweight } \\
15.7 \% \text { obese }\end{array}$ & USA (11) \\
\hline Learning disability & $19.3 \%$ obese & $12.2 \%$ obese & USA (13) \\
\hline Hearing or visual impairment & $18.4 \%$ obese & & \\
\hline Autism & $23.4 \%$ obese & & \\
\hline $\begin{array}{l}\text { Attention deficit (hyperactivity) } \\
\text { disorder }\end{array}$ & $18.9 \%$ obese & & \\
\hline Asthma & $19.7 \%$ obese & & \\
\hline Asthma & $24.6 \%$ overweight & $14.2 \%$ overweight & Denmark (14) \\
\hline \multicolumn{4}{|c|}{ b) Proportions in individual disabilities without comparison group *1 } \\
\hline Cerebral palsy (15) & \multicolumn{3}{|l|}{$29 \%$ overweight ${ }^{\star 2}$} \\
\hline Visual impairment (16) & \multicolumn{3}{|l|}{$25.8 \%$ overweight, $11.8 \%$ obese } \\
\hline $\begin{array}{l}\text { Attention deficit (hyperactivity) } \\
\text { disorder (17) }\end{array}$ & \multicolumn{3}{|l|}{$29 \%$ overweight, $17 \%$ obese } \\
\hline Autism (17) & \multicolumn{3}{|l|}{$35.7 \%$ overweight, $19 \%$ obese } \\
\hline Spina bifida (18) & \multicolumn{3}{|l|}{$18 \%$ obese } \\
\hline \multicolumn{4}{|c|}{$\begin{array}{l}\text { c) Other disabilities that are associated with overweight/obesity, but no prevalence data are available } \\
\text { from the literature }\end{array}$} \\
\hline \multicolumn{4}{|l|}{ - Prader-Willi syndrome (e24) } \\
\hline \multicolumn{4}{|l|}{ - Down's syndrome (e46) } \\
\hline \multicolumn{4}{|l|}{ - Muscular dystrophy (e47) } \\
\hline \multicolumn{4}{|l|}{ - Type I diabetes (e22) } \\
\hline \multicolumn{4}{|l|}{ - Juvenile arthritis (e22) } \\
\hline \multicolumn{4}{|c|}{ - Mental retardation (e21, e30, e48, e49) } \\
\hline
\end{tabular}

${ }^{* 1}$ To provide a comparison: In Germany, 8.7\% of children are overweight, and an additional $6.3 \%$ are obese (e11) $\star^{2}$ Other studies have reported a $50 \%$ reduced risk of overweight (e3)

apparent from as early as 3 years of age (odds ratio [OR] 1.3; 95\% confidence interval [CI] 1.01 to 1.67 for overweight in children with developmental delays), with further increases by the $5^{\text {th }}$ year of life (OR 1.8 [CI 1.23 to 2.54]) (e5). This trend continues into adulthood; consequently, adults with disabilities are more often overweight (OR up to 4.3, depending on the disorder; Table 2) (e6-e9). On the basis of representative data from the KIGGS study and an assumption of double the rate of overweight and obesity in disabled children, the total estimates for Germany are some 28000 overweight, and additionally 20000 obese, children and adolescents with disabilities.

\section{The consequences of obesity in children and adolescents with disabilities}

Studies in obese children and adolescents with disabilities have shown that cardiovascular risk factors were notably more common than in children with disabilities whose weight was normal (2, e12). For example, $42 \%$ of obese children and adolescents with spina bifida have either dyslipidemia or arterial hypertension, or both (2). However, for disabled children and adolescents, obesity primarily represents a crucial risk factor for the development and/or deterioration of secondary problems arising from the underlying disability. These include fatigue and pain owing to the 
TABLE 2

Odds ratio ( $95 \%$ confidence interval) for obesity in different adult diseases compared with healthy adults (19)

\begin{tabular}{l|l} 
Disease & Odds ratio \\
\hline Restricted mobility & $2.02(1.69$ to 2.43$)$ \\
\hline Back disorder & $1.84(1.58$ to 2.15$)$ \\
\hline Arthritis & $4.33(2.91$ to 6.45$)$ \\
\hline Learning disability & $2.43(1.97$ to 2.97$)$ \\
\hline Hearing impairment & $1.57(1.19$ to 2.07$)$ \\
\hline
\end{tabular}

strain on joints and muscles-caused by the excess weight — which can lead to impaired mobility and even a complete inability to walk-for example, in patients with spina bifida or cerebral palsy (1). Further, the observed social isolation can result in depression, which is particularly common in obese children with disabilities (3). All these chronic and secondary sequelae of obesity in disabled children and adolescents can lead to a total loss of their existing independence and thus further restrict their options for exercise, leisure activities, and later employment (e13). As a result, quality of life for these children-which is already lower than in their healthy peers (4) - is reduced even further $(1,4)$.

\section{Potential risk factors for obesity in children and adolescents with disabilities}

Awareness and an understanding of the risk factors for eating disorders are vital in order to develop effective preventive and therapeutic measures for obesity in children and adolescents with disabilities. Interestingly, one study has shown that the risk factors for overweight that apply to children without disabilities — such as social stratum and a migrant background-are not decisive in children with disabilities (e5). We will focus on 4 relevant areas for children with disabilities:

- Exercise

- Diet

- Awareness of and attention to obesity

- Social participation.

\section{Exercise}

Physical, sensory, or cognitive deficits often prevent disabled children from participating in particular kinds of sports or recreational sports with healthy children and adolescents. Complications arising from their underlying morbidity can also mean that disabled children cannot actively pursue exercise or sports. Pain, for example, is known to affect children with cerebral palsy (for example, as a result of cerebral palsy) or children who overuse certain muscle groups (for example, the shoulders in those using wheelchairs or walking aids) (1). Poor physical fitness, an impaired sense of balance, and poor physical coordination further impede active participation in sports groups (1, e14).

A lack of available facilities for disabled people constitutes another factor that precludes active exercise. Narrow footpaths or paths in a poor state of repair may present obstacles, as do lacking ramps for wheelchair access (5). The lack of facilities for people with disabilities in fitness centers, on playgrounds, and in sports centers constitutes further barriers to exercise. Most sports coaches and fitness center staff are not trained to look after children with disabilities (1). Overprotective parents may pose another obstacle for disabled children in that they may not allow their offspring to play outdoors. Unsafe neighborhoods may have the same effect, where children with disabilities may be at greater risk of accidents, vilified, or exposed to violence (6). Impaired mobility (18\%), financial expenses for special equipment (15\%), and lacking exercise facilities (10\%) have been described as the most common barriers to exercising for disabled children and adolescents (6).

In view of the many barriers to exercise it is hardly surprising that disabled children consume more television and computer games (1, e15, e16). This kind of behavior is also associated with obese children without disabilities (e17). An association between media consumption and obesity has been shown particularly for children with infantile cerebral palsy (e18, e19), spina bifida (e20), mental retardation (e21), asthma (e22), or impaired physical mobility (e22).

\section{Diet}

Special dietary habits among children and adolescents with disabilities can substantially increase the risk of obesity.

Some children with autism spectrum disorders, for example, tend to eat only highly calorific foods (e23). Children with Prader-Willi syndrome, craniopharyngioma, Down's syndrome, or spina bifida have a predisposition to overeat, since the cerebral regions that are responsible for weight regulation (hypothalamus) may be damaged (e24, e25). Some parents tend to offer their disabled children more sweets, be this for reasons of increased stress, to calm down the children, or for fear of not providing their child with sufficient pleasure and joy (1).

Frequent food consumption as a consolation for sadness, boredom, or loneliness may also result in overweight in disabled children and adolescents (1).

\section{Awareness of and attention to obesity}

Often, a lack of knowledge and awareness of what constitutes a healthy lifestyle predisposes disabled people to a higher risk of obesity. Adolescents with a cognitive disability, for example, know less about the health risks that are associated with obesity (1, e26). Therapists may actually support this lack of awareness by failing to address the problem of overweight or weight gain with the children and adolescents and their families. 


\section{Social participation}

Mental and physical disabilities, behavioral problems, and learning difficulties impair social contact between children and adolescents with disabilities and their healthy peers. Exercise competence, which is often reduced in disabled children and adolescents, is also important for successful participation in community life (e21, e27).

Disabled people's frequent lack of participation commonly triggers feelings of isolation and entails a risk of excessive eating as a compensatory mechanism for this social deficit.

Stevens et al. reported that adolescents with impaired mobility encounter difficulties in forging friendships, which in turn results in lowered social integration (e28). Children with mental retardation play less often with other children compared with their healthy peers (e28). Children with cerebral palsy are often not accepted by their class mates, have fewer social contacts, and experience a higher rate of teasing (e30, e31). Other socially limiting factors include negative prejudices towards disabled people from the persons surrounding them, but also unusual behavior and language difficulties affecting disabled children themselves.

Many young wheelchair users are also excluded from social events by the sheer fact that the houses of their friends, restaurants, or public institutions lack ramps. All these factors result in exclusion from many school programs as well as community based programs (1).

Low self esteem, a negative body image or self image, increased stress, and low ability to socialize therefore in many cases result from multiple disabilities and may lead to emotional problems or learning difficulties, which in turn limit social participation (1).

\section{Prevention of and interventions for obesity in disabled children and adolescents}

By German law (SGB IX, rehabilitation and participation of disabled people), people with, or those threatened by, disabilities have the right to receive support from rehabilitation services in order to promote their autonomy and equal participation in community life, and avoid or counteract discrimination.

In Germany, the adoption of SGB IX included crucial aspects from the International Classification of Functioning, Disability and Health (ICF). In this biopsychosocial model (Figure), the aim is to restore or at least substantially improve functioning, especially in the areas of activity (as in a person performing a task or activity) and the participation of a person.

Important tasks of health and social policy, as well as disability and human rights policy therefore include:

- Abolishing obstacles in society and environmental factors that make participation difficult or impossible

- To extend supporting factors and facilities that restore or support participation in spite of substantial health impairment.

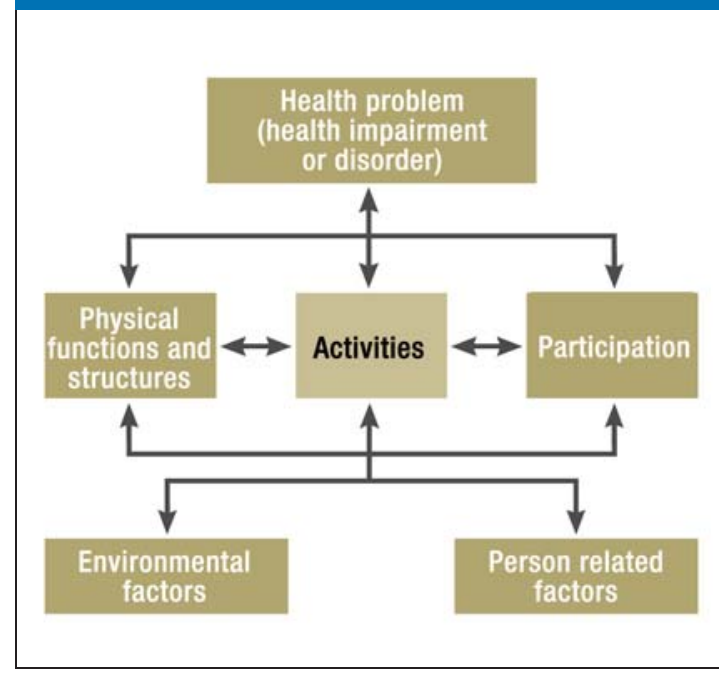

The biopsychosocia model of the International Classification of Functioning Disability and Health (ICF)

\section{BOX 1}

Pediatric patient groups with obesity without tailored therapeutic service provision (1)

- Obese children and adolescents with physical disabilities_for example, spina bifida, infantile cerebral palsy

- Obese children and adolescents with mental disabilities/syndromes such as Down's syndrome

- Obese children and adolescents with chronic diseases-such as juvenile rheumatoid arthritis, asthma, or type I diabetes

- Obese children and adolescents with impaired weight regulation owing to damage to cerebral regions that are responsible for feelings of satiety (for example, craniopharyngioma or MC4 receptor mutation)

- Obese children and adolescents with behavioral disorders or psychiatric disorders 
TABLE 3

Examples of positive effects of a lifestyle intervention* ${ }^{1}$

\begin{tabular}{l|l}
$\begin{array}{l}\text { Physical disability/chronic } \\
\text { disease }\end{array}$ & $\begin{array}{l}\text { Possible additional positive effects of reducing } \\
\text { weight }\end{array}$ \\
\hline Spina bifida & Maintaining ability to walk/run \\
\hline $\begin{array}{l}\text { Juvenile arthritis } \\
\text { Type I diabetes }\end{array}$ & Protecting the joints \\
\hline Improving metabolic status \\
\hline $\begin{array}{l}\text { Neuromuscular disorder: } \\
\text { - For example, Duchenne } \\
\text { muscular dystrophy } \\
\text { - Cerebral palsy }\end{array}$ & Improving metabolic status \\
\hline Asthma & Improving breathing \\
\hline Congenital heart defect & Increased physical exercise capacity \\
\hline
\end{tabular}

${ }^{* 1}$ Based on increased exercise and dietary change in obese children with disabilities and/or chronic disease (1)

The German Medical Association's 2009 annual general meeting, the German Medical Assembly (Deutscher Ärztetag) in Mainz, has once again underlined these requirements (7).

In spite of these legal foundations, however, the prevention or treatment of overweight in disability have not been tackled by researchers nor healthcare providers, so that obese disabled or chronically ill children and adolescents are an underprovided group in our healthcare system (Box 1) (1). This may also be due to the fact that health insurers have thus far not sufficiently financially supported such measures.

In reality, the barriers to a healthy living environment for disabled children and adolescents are actually sustained by our healthcare system, and social participation is made difficult, because disability is among the exclusion criteria for participation in a lifestyle intervention for obese children and adolescents (see consensus paper of the national associations of health insurers [8]). On the other hand, the complexity of the underlying illness in obese patients with chronic diseases and disabilities usually also precludes participation in the existing outpatient or inpatient treatment measures. Further, because individual disorders are uncommon, not all necessary experts can be brought together in one place-except in specialized institutions-so as to coordinate the treatment of obesity with that of the chronic disease or disability.

\section{Advantages of early treatment}

Offering a health intervention in obese children or adolescents with disabilities is likely to have many benefits: if overweight is reduced successfully, its harmful sequelae can often be reduced and many secondary sequelae in disabilities can be improved. This, in turn, has a positive impact on the underlying disease and the quality of life of the affected children (Table 3) (1).

\section{Aims of the intervention}

Disabled children and adolescents should be enabled to control their weight independently as far as possible by means of their own health behavior. Further intervention aims are listed in Box 2.

Because of the heterogeneity of the pathologies in disabled children, the extent to which the treatment should focus on obesity should always be considered.

It needs to be borne in mind whether, and how, an intervention is feasible in view of the limited scope for activity among disabled children and adolescents.

It also needs to be considered to what extent obesity contributes to a reduced quality of life, and whether the quality of life can be improved by treatment.

Attention should also be paid to whether there is really any excess fat present because, on the one hand, adolescents whose weight is normal perceive themselves as overweight (e32), and, on the other hand, some children with disabilities have a different body composition so that the BMI as applied elsewhere may not reflect the body fat proportion accurately in this group. One study, for example, showed that, in contrast to healthy children, BMI and body composition correlate only to a degree in disabled children (e33).

\section{Designing the intervention}

Effective health promotion for children and adolescents with disabilities should be geared towards their abilities and interests and take into account their physical, cognitive, and/or sensory impairments.

Little is known about effective prevention or intervention measures for obesity in children and adolescents without disabilities (9, e34, e35). It is therefore hardly surprising that very few studies published to date have investigated the prevention and treatment of overweight in children and adolescents with disabilities (1): An interdisciplinary lifestyle intervention over 16 weeks, with the emphasis on exercise and nutrition/ diet, resulted in improved physical fitness in 11- to 18-year-old children and adolescents with spina bifida, but it did not succeed in reducing participants' overweight (e36).

The same results also applied for short term lifestyle interventions for children with infantile cerebral palsy (e37, e38) or Down's syndrome (e39). Long term studies in children and adolescents are lacking.

Experiences in the treatment of obese children and adolescents without disabilities (8, 10, e34, e35, e40) have shown that what is required is long term treatment in a multidisciplinary setting. Such a setting would include dieticians, psychologists, exercise specialists, and doctors (who ideally should also be specialized in treating the disabilities of children and adolescents) (6). Crucially, the parents should also be included, so that fears and anxieties relating to exercise can be reduced, overprotecting behavior should be discussed, familial eating habits elucidated, and alternatives given if eating 


\section{Intervention targets in obese children with disabilities or chronic diseases}

- Long term reduction of overweight and weight stabilization

- In children and adolescents, keeping their weight constant over a lengthy period of time can be a sufficient therapeutic goal if they have not yet reached their full height

- Improving eating and exercise behaviors of patients by including their families

- Improving obesity associated comorbidities including secondary sequelae of the disability that are aggravated by obesity

- Avoiding adverse therapeutic effects

- Promoting normal physical, psychological, and social development and performance capability, as far as possible

- Age appropriate, suitable interaction of patients with their social environment or families supports treatment; however, this also means promoting an independent lifestyle; to achieve a normal psychological development it may be necessary to deprioritize medical treatment temporarily

- Improving physical performance

- Improving psychosocial status

- Improving psychological functioning

- Developing a strategy for long term behavioral modification (case management)

- Providing appropriate career advice for adolescents, based on their inclinations and skills, in order to facilitate social participation as much as possible

\section{BOX 3}

\section{Doctors who treat disabled children and adolescents should}

- be aware of the importance of exercise and diet in disabled patients

- recognize the barriers to exercise and healthy diet and explain these to the patients and their families

- support the families in creating appropriate exercise options/regimens

- advise families and carers about what active exercise provisions are available (if required, by using exercise adjuvants)

- advise families and carers on which diet is appropriate for disabled children or adolescents whose exercise capacity may be reduced

- monitor the weight development of the disabled children or adolescents, and in case of rapid weight increase inform patients, their families, and their carers about the overweight and its individual effects on the underlying disease

- be aware of suitable exercise programs (for example, wheelchair sports groups) and nutrition/diet programs within the region and make these available to affected families. 
is a redirection activity compensating for social restriction (6, e41, e42). As when treating obese children without disabilities, no rigid or restrictive diet plans should be used, but low fat and low sugar alternatives that are consistent with an optimized varied diet should be worked out in collaboration with the parents and carers $(8,10$, e34, e35, e40). Ideally, the intervention should give the children pleasure. The ideal solution for this is exercise therapy. In children and adolescents with or without disabilities, exercise promotes muscular strength and physical fitness (e43), reduces stereotypical movement patterns (e44) and thus reduces pain and fatigability (e15, e45). Exercise promotes friendships, creativity, integration, social acceptance, self confidence, and, ultimately, quality of life (6, e43). Increasing muscular strength and physical fitness additionally reduce injuries, osteoporosis, or bone fractures, as well as dependence on others (6, e15).

\section{Simple measures to prevent and treat obesity}

The fact that thus far, treatment results in obese children and adolescents without disabilities (9) have been mostly unsatisfactory, probably means that effective therapeutic measures in obese children and adolescents with disabilities will not be easily achieved. However, this fact alone should not stop therapists from tackling the problem of overweight in children and adolescents with disabilities. Simple measures that all doctors who look after children and adolescents with disabilities can conduct are summarized in Box 3.

If these measures remain unsuccessful, treatment is required in institutions that specialize in obesity therapy but also in the complexity of the individual disabilities in children and adolescents. Such specialized institutions cannot, however, be realized without special funding from the health insurers.

\section{KEY MESSAGES}

- Chronically ill children and adolescents and those with disabilities have an increased risk for overweight and obesity. The risk groups include primarily children and adolescents with spina bifida, functional mobility impairments, developmental delays, learning difficulties, mental retardation, audiovisual impairments, autism, attention deficit (hyperactivity) disorder, asthma, or juvenile arthritis.

- Obesity in disabled or chronically ill children and adolescents worsens the complications that arise from the disability itself and further restricts participation and quality of life of the affected children and adolescents.

- Obese children and adolescents with disabilities cannot be treated according to established therapeutic and training plans for obese children and adolescents.

- Specially structured, sustainable, effective prevention and intervention programs for obese children and adolescents with disabilities are thus far lacking.

- What is urgently needed are specialized therapeutic institutions for obesity therapy as well as for the complex individual disability, but these cannot be realized without special financial support/funding from the health insurers.

\section{Conflict of interest statement}

Thomas Reinehr has received financial support from the Federal Ministry of Education and Research (BMBF) in the context of the German Competence Network for Obesity of the LARGE (Longitudinal Childhood Adiposity Research in Germany) project (grant No. 01 Gl0839).

Michael Dobe, Katrin Winke, Anke Schaefe, and Dieter Hoffmann declare that no conflict of interests exists according to the guidelines of the International Committee of Medical Journal Editors.

Manuscript received on 15 June 2009, revised version accepted on 24 August 2009

Translated from the original German by Dr Birte Twisselmann.

\section{REFERENCES}

1. Rimmer JH, Rowland JL, Yamaki K: Obesity and secondary conditions in adolescents with disabilities: addressing the needs of an underserved population. J Adolesc Health 2007; 41: 224-9.

2. Buffart LM, van den Berg-Emons RJ, Burdorf A, Janssen WG, Stam HJ, Roebroeck ME: Cardiovascular disease risk factors and the relationships with physical activity, aerobic fitness, and body fat in adolescents and young adults with myelomeningocele. Arch Phys Med Rehabil 2008; 89: 2167-73

3. Liou TH, Pi-Sunyer FX, Laferrere B: Physical disability and obesity. Nutr Rev 2005; 63: 321-31.

4. Buffart LM, Berg-Emons RJ, Meeteren JV, Stam HJ, Roebroeck ME: Lifestyle, participation, and health-related quality of life in adolescents and young adults with myelomeningocele. Dev Med Child Neurol 2009 (Epub ahead of print).

5. Rimmer JH: The conspicuous absence of people with disabilities in public fitness and recreation facilities: lack of interest or lack of access? Am J Health Promot 2005; 19: 327-9.

6. Murphy NA, Carbone PS: Promoting the participation of children with disabilities in sports, recreation, and physical activities. Pediatrics 2008; 121: 1057-61.

7. Klinhammer G, Gieseke S: Menschen mit Behinderung: Auf engagierte ärztliche Hilfe angewiesen. Dtsch Arztebl 2009; (106)22: 1094-7.

8. Leitlinie der Arbeitsgemeinschaft Adipositas im Kindes- und Jugendalter. http//www.a-g-a.de/Leitlinie.pdf. Guidelines of the German working group on obese children and adolescents. 2009.

9. Reinehr T, Widhalm K, l'Allemand D, Wiegand S, Wabitsch M, Holl RW: Two-year follow-up in 21,784 overweight children and adolescents with lifestyle intervention. Obesity (Silver Spring) 2009; 17: 1196-9.

10. Reinehr T, Dobe M, Kersting M: Therapie der Adipositas im Kindesund Jugendalter: Schulung Obeldicks und Obeldicks Light. $2^{\text {nd }}$ edition. Hogrefe Verlag; 2009.

11. Bandini LG, Curtin C, Hamad C, Tybor DJ, Must A: Prevalence of overweight in children with developmental disorders in the continuous national health and nutrition examination survey (NHANES) 1999-2002. J Pediatr 2005; 146: 738-43.

12. De S, Small J, Baur LA: Overweight and obesity among children with developmental disabilities. J Intellect Dev Disabil 2008; 33: 43-7.

13. Chen AY, Kim SE, Houtrow AJ, Newacheck PW: Prevalence of Obes ity Among Children With Chronic Conditions. Obesity (Silver Spring). 2009 (Epub ahead of print).

14. Vahlkvist S, Pedersen S: Fitness, daily activity and body composition in children with newly diagnosed, untreated asthma. Allergy 2009 (Epub ahead of print).

15. Hurvitz EA, Green LB, Hornyak JE, Khurana SR, Koch LG: Body mass index measures in children with cerebral palsy related to gross motor function classification: a clinic-based study. Am J Phys Med Rehabil 2008; 87: 395-403.

16. Montero P: Nutritional assessment and diet quality of visually impaired Spanish children. Ann Hum Biol 2005; 32: 498-512.

17. Curtin C, Bandini LG, Perrin EC, Tybor DJ, Must A: Prevalence of overweight in children and adolescents with attention deficit hyperactivity disorder and autism spectrum disorders: a chart review. BMC Pediatr 2005; 5: 48. 
18. Dosa NP, Foley JT, Eckrich M, Woodall-Ruff D, Liptak GS: Obesity across the lifespan among persons with spina bifida. Disabil Rehabil 2008; $1-7$.

19. Ells LJ, Lang R, Shield JP, et al.: Obesity and disability—a short review. Obes Rev 2006; 7: 341-5

\section{Corresponding author}

Prof. Dr. med. Thomas Reinehr

Institut für Pädiatrische Ernährungsmedizin

Vestische Kinder- und Jugendklinik Datteln, Universität Witten/Herdecke

Dr.-F.-Steiner-Str. 5

5711 Datteln, Germany

T.Reinehr@kinderklinik-datteln.de

(2) For e-references please refer to:

www.aerzteblatt-international.de/ref1510 


\title{
Obesity in Disabled Children and Adolescents
}

\author{
An Overlooked Group of Patients
}

Thomas Reinehr, Michael Dobe, Katrin Winkel, Anke Schaefer, Dieter Hoffmann

\section{E-References}

e1. Stallings VA, Charney EB, Davies JC, Cronk CE: Nutritional status and growth of children with diplegic or hemiplegic cerebral palsy. Dev Med Child Neurol 1993; 35: 997-1006.

e2. Stallings VA, Cronk CE, Zemel BS, Charney EB: Body composition in children with spastic quadriplegic cerebral palsy. J Pediatr 1995; 126: 833-9.

e3. Velez JC, Fitzpatrick AL, Barbosa Cl, Diaz M, Urzua M, Andrade AH: Nutritional status and obesity in children and young adults with disabilities in Punta Arenas, Patagonia, Chile. Int J Rehabil Res 2008; 31: 305-13.

e4. Cole TJ, Bellizzi MC, Flegal KM, Dietz WH: Establishing a standard definition for child overweight and obesity worldwide: international survey. BMJ 2000; 320: 1240-3.

e5. Emerson E: Overweight and obesity in 3- and 5-year-old children with and without developmental delay. Public Health 2009; 123: 130-3.

e6. Yamaki K: Body weight status among adults with intellectual disability in the community. Ment Retard 2005; 43: 1-10.

e7. Hove 0 : Weight survey on adult persons with mental retardation living in the community. Res Dev Disabil 2004; 25: 9-17.

e8. Melville CA, Hamilton S, Hankey CR, Miller S, Boyle S: The prevalence and determinants of obesity in adults with intellectual disabilities. Obes Rev 2007; 8: 223-30.

e9. Hamilton S, Hankey CR, Miller S, Boyle S, Melville CA: A review of weight loss interventions for adults with intellectual disabilities. Obes Rev 2007; 8: 339-45.

e10. Henderson A, Lynch SA, Wilkinson S, Hunter M: Adults with Down's syndrome: the prevalence of complications and health care in the community. Br J Gen Pract 2007; 57: 50-5.

e11. Kurth BM, Schaffrath RA: The prevalence of overweight and obese children and adolescents living in Germany. Results of the German Health Interview and Examination Survey for Children and Adolescents (KiGGS). Bundesgesundheitsblatt Gesundheitsforschung Gesundheitsschutz 2007; 50: 736-43.

e12. Rimmer JH, Braddock D, Fujiura G: Cardiovascular risk factor levels in adults with mental retardation. Am J Ment Retard 1994; 98: 510-8.

e13. Simeonsson RJ, McMillen JS, Huntington GS: Secondary conditions in children with disabilities: spina bifida as a case example. Ment Retard Dev Disabil Res Rev 2002; 8: 198-205.

e14. Hutzler Y, Chacham A, Bergman U, Szeinberg A: Effects of a movement and swimming program on vital capacity and water orientation skills of children with cerebral palsy. Dev Med Child Neurol 1998; 40: 176-81.

e15. U.S. Department of Health and Human Services, Healthy People 2010 ( $2^{\text {nd }}$ ed.). 2000.

e16. Stuifbergen AK, Roberts GJ: Health promotion practices of women with multiple sclerosis. Arch Phys Med Rehabil 1997; 78: 3-9. e17. Giammattei J, Blix G, Marshak HH, Wollitzer AO, Pettitt DJ: Television watching and soft drink consumption: associations with obesity in 11- to 13-year-old schoolchildren. Arch Pediatr Adolesc Med 2003; 157: 882-6.

e18. van den Berg-Emons HJ, Saris WH, de B, Westerterp KR, Huson A, van Baak MA: Daily physical activity of schoolchildren with spastic diplegia and of healthy control subjects. J Pediatr 1995; 127: $578-84$.

e19. Maltais DB, Pierrynowski MR, Galea VA, Matsuzaka A, Bar-Or O: Habitual physical activity levels are associated with biomechanical walking economy in children with cerebral palsy. Am J Phys Med Rehabil 2005; 84: 36-45.

e20. Buffart LM, Roebroeck ME, Rol M, Stam HJ, van den Berg-Emons RJ: Triad of physical activity, aerobic fitness and obesity in adolescents and young adults with myelomeningocele. J Rehabil Med 2008; 40: 70-5.

e21. Frey GC, Chow B: Relationship between BMI, physical fitness, and motor skills in youth with mild intellectual disabilities. Int J Obes (Lond) 2006; 30: 861-7.

e22. Gannotti M, Veneri D, Roberts D: Weight status and physical activity in third graders with chronic health conditions. Pediatr Phys Ther 2007; 19: 301-8.

e23. Schreck KA, Williams K, Smith AF: A comparison of eating behaviors between children with and without autism. J Autism Dev Disord 2004; 34: 433-8.

e24. van Mil EG, Westerterp KR, Gerver WJ, Van Marken Lichtenbelt WD, Kester AD, Saris WH: Body composition in Prader-Willi syndrome compared with nonsyndromal obesity: Relationship to physical activity and growth hormone function. J Pediatr 2001; 139: 708-14.

e25. Luke A, Sutton M, Schoeller DA, Roizen NJ: Nutrient intake and obesity in prepubescent children with Down syndrome. J Am Diet Assoc 1996; 96: 1262-7.

e26. Jobling A: Beyond sex and cooking: health education for individuals with intellectual disability. Ment Retard 2001; 39: 310-21.

e27. Okely AD, Booth ML, Chey T: Relationships between body composition and fundamental movement skills among children and adolescents. Res Q Exerc Sport 2004; 75: 238-47.

e28. Stevens SE, Steele CA, Jutai JW, Kalnins IV, Bortolussi JA, Biggar WD: Adolescents with physical disabilities: some psychosocial aspects of health. J Adolesc Health 1996; 19: 157-64.

e29. Guralnick MJ: Peer social networks of young boys with developmental delays. Am J Ment Retard 1997; 101: 595-612.

e30. Murphy CM, Allison DB, Babbitt RL, Patterson HL: Adiposity in children: is mental retardation a critical variable? Int J Obes Relat Metab Disord 1992; 16: 633-8.

e31. Nadeau L, Tessier R: Social adjustment at school: Are children with cerebral palsy perceived more negatively by their peers than other at-risk children? Disabil Rehabil 2009; 31: 302-8. 
e32. Kurth BM, Ellert U: Perceived or true obesity: which causes more suffering in adolescents? [Gefühltes oder tatsächliches Übergewicht: Worunter leiden Jugendliche mehr? Ergebnisse des Kinderund Gesundheitssurveys KiGGS]. Dtsch Arztbl Int 2008;105(53): 406-12.

e33. Warner JT, Cowan FJ, Dunstan FD, Gregory JW: The validity of body mass index for the assessment of adiposity in children with disease states. Ann Hum Biol 1997; 24: 209-15.

e34. Barlow SE, Dietz WH: Management of child and adolescent obesity: summary and recommendations based on reports from pediatricians, pediatric nurse practitioners, and registered dietitians. Pediatrics 2002; 110: 236-8.

e35. Ebbeling CB, Pawlak DB, Ludwig DS: Childhood obesity: publichealth crisis, common sense cure. Lancet 2002; 360: 473-82.

e36. Liusuwan RA, Widman LM, Abresch RT, Johnson AJ, McDonald $\mathrm{CM}$ : Behavioral intervention, exercise, and nutrition education to improve health and fitness (BENEfit) in adolescents with mobility impairment due to spinal cord dysfunction. J Spinal Cord Med 2007; 30 Suppl 1: 119-26.

e37. Rimmer JH: Physical fitness levels of persons with cerebral palsy. Dev Med Child Neurol 2001; 43: 208-12

e38. Fowler EG, Kolobe TH, Damiano DL, et al.: Promotion of physical fitness and prevention of secondary conditions for children with cerebral palsy: section on pediatrics research summit proceedings. Phys Ther 2007; 87: 1495-1510.

e39. Wind WM, Schwend RM, Larson J: Sports for the physically challenged child. J Am Acad Orthop Surg 2004; 12: 126-37.

e40. Summerbell CD: The identification of effective programs to prevent and treat overweight preschool children. Obesity (Silver Spring) 2007; 15: 1341-2. e41. Patel DR, Greydanus DE: The pediatric athlete with disabilities. Pediatr Clin North Am 2002; 49: 803-27.

e42. King G, Law M, King S, Rosenbaum P, Kertoy MK, Young NL: A conceptual model of the factors affecting the recreation and leisure participation of children with disabilities. Phys Occup Ther Pediatr 2003; 23: 63-90.

e43. Dykens EM, Rosner BA, Butterbaugh G: Exercise and sports in children and adolescents with developmental disabilities. Positive physical and psychosocial effects. Child Adolesc Psychiatr Clin N Am 1998; 7: 757-71, viii.

e44. Fragala-Pinkham MA, Dumas HM, Barlow CA, Pasternak A: An aquatic physical therapy program at a pediatric rehabilitation hospital: a case series. Pediatr Phys Ther 2009; 21: 68-78.

e45. McBurney H, Taylor NF, Dodd KJ, Graham HK: A qualitative analysis of the benefits of strength training for young people with cerebral palsy. Dev Med Child Neurol 2003; 45: 658-63.

e46. Cronk C, Crocker AC, Pueschel SM, et al.: Growth charts for children with Down syndrome: 1 month to 18 years of age. Pediatrics 1988; 81: 102-10.

e47. Zanardi MC, Tagliabue A, Orcesi S, Berardinelli A, Uggetti C, Pichiecchio A: Body composition and energy expenditure in Duchenne muscular dystrophy. Eur J Clin Nutr 2003; 57: 273-8.

e48. Rimmer JH, Yamaki K: Obesity and intellectual disability. Ment Retard Dev Disabil Res Rev 2006; 12: 22-7.

e49. Takeuchi E: Incidence of obesity among school children with mental retardation in Japan. Am J Ment Retard 1994; 99: 283-8. 